\title{
BIOMETRIA DE CACHOS, FRUTOS E SEMENTES E GERMINAÇÃO DE JACIARANA (Syagrus sancona H. Karsten. ARECACEAE).
}

\author{
Pedro Raimundo Ferreira de Lima ${ }^{1}$, Evandro José Linhares Ferreira ${ }^{2}$ \\ ${ }^{1}$ Graduando do Curso de Engenheira Florestal da Universidade Federal do Acre \& \\ Bolsista de Iniciação Científica do Instituto Nacional de Pesquisas da Amazônia- \\ INPA, Rio Branco, Acre. (pedro.f5@hotmail.com). \\ ${ }^{2}$ Engenheiro Agrônomo, Doutor em Botânica, Pesquisador Sênior do Instituto \\ Nacional de Pesquisas da Amazônia - INPA, Rio Branco, Acre.
}

Recebido em: 08/04/2017 - Aprovado em: 10/06/2017 - Publicado em: 20/06/2017 DOI: 10.18677/EnciBio_2017A25

\begin{abstract}
RESUMO
A jaciarana (Syagrus sancona) é uma palmeira com ampla distribuição ao norte, oeste e sul da região Amazônica. No Acre ela ocorre em florestas primárias, secundárias e áreas de pastagens. Seus frutos são oleaginosos e em cultivo ela produz anualmente até 19 toneladas/frutos/hectares. Diante disso, neste estudo avaliaram-se parâmetros biométricos de cachos, frutos e sementes, e a germinação de sementes de $S$. sancona. Os resultados mostram cachos com 131,8 cm de comprimento médio e peso médio de $13,1 \mathrm{~kg}$. A média de frutos/cacho foi 1.258 e a quantidade média de raquilas 164. A despeito do emprego de diferentes tratamentos para a quebra de possível dormência, foi observado um baixo porcentual na germinação e um tempo médio de germinação elevado (113 dias), dentro do esperado para as espécies de palmeiras, que usualmente superam os 100 dias. A duração da emergência de plântulas também se mostrou lenta, pois passados quase oito meses da semeadura, ela ainda estava acontecendo. Dos tratamentos avaliados, a imersão das sementes em água por 24 e 72 horas, respectivamente, assim como a escarificação dos frutos para a remoção da película protetora do poro germinativo resultaram em maiores percentuais de emergência de plântulas. Diante da escassez na literatura científica de estudos abordando a biometria e outros aspectos relacionados com a propagação de espécies do gênero Syagrus, pode-se inferir que o desenvolvimento de sistemas de propagação vegetativo eficientes para S. sancona demandará um intenso esforço de pesquisa.
\end{abstract}

PALAVRAS-CHAVE: Amazônia, Propagação, Sementes Florestais.

\section{BIOMETRY OF BUNCHES, FRUIT AND SEEDS AND GERMINATION OF JACIARANA (Syagrus sancona H. Karsten, ARECACEAE).}

\footnotetext{
ABSTRACT

The jaciarana (Syagrus sancona) is a palm tree widely distributed to the north, west and south of the Amazon region. In Acre it occurs in primary and secondary forests, and pasture areas. Its fruits are oleaginous and in cultivation it produces annually up to 19 tons/fruits/hectares. In this study, the biometric characteristics of the bunches, fruits and seeds, and the germination of $S$. sancona seeds were evaluated. The ENCICLOPÉDIA BIOSFERA, Centro Científico Conhecer - Goiânia, v.14 n.25; p.267 2017
} 
results show bunches with $131.8 \mathrm{~cm}$ of average length and average weight of 13.1 $\mathrm{kg}$. The mean number of fruits/bunch was 1,258 and the mean number of rachillae 164. Despite the use of different treatments for the breakdown of possible dormancy, a low percentage of germination and a high mean time of germination (113 days) were observed, although expected for palm species, which usually exceed 100 days. The duration of seedlings emergence was also slow, because after almost eight months of sowing, it was still happening. Of the evaluated treatments, the seed immersion in water for 24 and 72 hours, respectively, as well as the scarification of the fruits for the removal of the protective layer of the germinative pore resulted in greater percentages of emergence. Due to the scarcity of scientific literature of studies addressing biometrics and other aspects related to the propagation of Syagrus species in general, it can be inferred that the development of efficient vegetative propagation systems for $S$. sancona will require an intensive research effort.

KEYWORDS: Propagation, Forest Seeds, Amazon

\section{INTRODUÇÃO}

A jaciarana (Syagrus sancona) é uma espécie de palmeira de porte mediano com ampla distribuição ao norte, oeste e sul da região Amazônica, onde é considerada uma espécie de ocorrência rara em áreas florestais (HENDERSON, 1995). No Acre ela ocorre em florestas primárias, secundárias e áreas de pastagens, sendo, entretanto, mais comum nas bordas de fragmentos florestais (FERREIRA, 2005). Os frutos dessa espécie são oleaginosos e em cultivo experimental na área do Parque Zoobotânico (PZ) da Universidade Federal do Acre (UFAC), em Rio Branco, Acre, sua produção anual foi estimada em até 19 toneladas/frutos/hectares, um valor elevado considerando que o dendê (Elaeis guineensis Jacq.), a palmeira oleaginosa cultivada mais produtiva, produz entre 25 e 28 t/frutos/ha/ano (FERREIRA et al., 2013; LEBID \& HENKES, 2015).

O grande potencial de produção de frutos e o possível aproveitamento de seu conteúdo oleaginoso sugerem que a viabilidade técnica do cultivo da espécie precisa ser estudada. Nesse sentido, a realização de estudos biométricos de seus cachos, frutos e sementes é importante porque pode fornecer informações que viabilizem meios eficientes de propagação, além de permitir a diferenciação de possíveis variações genéticas existentes entre populações espontâneas da mesma em áreas silvestres (BEZERRA et al., 2012; GONÇALVES et al., 2013).

Em se tratando de palmeiras, a forma mais eficiente de fazer sua propagação é quase que exclusivamente realizada mediante o uso de sementes (SMIDERLE et al., 2015). Entretanto, a maioria das espécies de palmeiras apresenta germinação lenta e desuniforme, estimando-se que em pelo menos $25 \%$ de todas as espécies o tempo para a germinação exceda os 100 dias e o percentual de germinação seja inferior a $20 \%$ em razão de fatores fisiológicos e ambientais (MEEROW \& BROSCHAT, 2012; RODRIGUES et al., 2016).

Conhecer sobre a germinação de sementes de uma espécie é essencial para entender sua forma de propagação, desenvolver estratégias para fomentar a silvicultura e a conservação (BUSATTO et al., 2013; SILVA et al., 2016), e observar a influencia dos fatores ambientais nos processos fisiológicos e morfológicos do embrião e da plântula (GORDIN et al. 2012). 
No caso de Syagrus sancona (Kunth) H.Karst., um estudo preliminar realizado por pesquisadores do PZ/UFAC em Rio Branco, Acre (dados não publicados), sugeriu a ocorrência de algum tipo de dormência nas sementes, que demoram pelo menos 300 dias para germinar. Esta condição não é incomum em outras espécies de Syagrus. Em S. oleracea, a única espécie de Syagrus nativa do Brasil cultivada para a produção de palmito, as sementes apresentam germinação lenta e desuniforme (PINTO et al., 2012).

Assim, o presente estudo objetivou determinar características biométricas de cachos, frutos e sementes, e avaliou características do processo de germinação das sementes de $S$. sancona.

\section{MATERIAL E MÉTODOS}

Nove cachos com frutos maduros de $S$. sancona foram colhidos manualmente de nove plantas matrizes cultivadas na área do Parque Zoobotânico $(P Z)$, na área do campus da UFAC, em Rio Branco, Acre (957'27"S; 67ํ52'24"W). Após a colheita, os cachos foram levados para o laboratório multidisciplinar do Núcleo de pesquisas do INPA em Rio Branco. Os cachos foram pesados individualmente em balança tipo plataforma com capacidade de $160 \mathrm{~kg}$. Após a pesagem, foram contadas todas as raquilas e frutos de cada cacho. Depois disso, foram selecionadas de forma aleatória, e removidas com auxílio de um estilete, 10 raquílas da base, meio e ápice de cada cacho para medição do comprimento, pesagem e contagem dos frutos. $\mathrm{Da}$ raque do cacho mediu-se o comprimento e o diâmetro na base, meio e ápice utilizando-se uma trena.

A avaliação morfométrica dos frutos e das sementes de $S$. sancona foi feita no Laboratório de Sementes Florestais do PZ. A avaliação foi baseada na metodologia empregada por NASCIMENTO et al. (2007) e DOMINGOS-NETO \& FERREIRA (2014). De um lote com 200 frutos sadios e maduros foram selecionadas 200 sementes. Os frutos e as sementes foram pesados em balança de precisão $(0,001 \mathrm{~g})$ e um paquímetro digital foi usado para medir o comprimento, a largura e espessura $(\mathrm{cm})$, e a profundidade de polpa $(\mathrm{cm})$ dos frutos e sementes. Foram avaliados, dos frutos, o peso total, o comprimento, o diâmetro e a profundidade da polpa. Após a avaliação os frutos foram despolpados para permitir a extração das sementes, que foram lavadas em água corrente e colocadas para secar em temperatura ambiente no laboratório. As sementes (pirênios compostos por endocarpo completo + endosperma) foram avaliadas quanto ao peso, comprimento e diâmetro.

O experimento de germinação foi realizado na casa de vegetação do viveiro do PZ. Para a avaliação da germinação, foram utilizados pirênios (endocarpo intacto + endosperma) tendo em vista que estes últimos são muito aderidos e dificilmente podem ser retirados sem sofrer danos. Utilizou-se o delineamento experimental de blocos casualizados em esquema fatorial $2 \times 6$ com quatro repetições de 25 sementes. Os fatores avaliados foram frutos e sementes beneficiados, submetidos aos seguintes tratamentos: T1 = Frutos e sementes intactas; T2 = imersão em água por 12 horas; T3 = imersão em água por 24 horas; T4 = imersão em água por 48 horas; T5 = imersão em água por 72 horas (PINTO et al. 2012); T6 = escarificação do poro germinativo para a retirada da película protetora do poro germinativo (FIOR et al., 2013). A determinação do grau de umidade foi realizada em quatro repetições de 10 sementes, adotando-se o método de estufa a $105 \pm 3{ }^{\circ} \mathrm{C}$, durante 24 horas (BRASIL, 1992). 
Foi utilizado como substrato a areia lavada e como recipientes bandejas plásticas (50 cm de comprimento $\times 20 \mathrm{~cm}$ de largura $\times 6 \mathrm{~cm}$ de altura) irrigadas a cada dois dias e monitoradas diariamente. Depois de semeadas, as sementes foram cobertas com uma camada aproximada de $1,0 \mathrm{~cm}$ de espessura de areia.

O programa Microsoft Office Excel 2007 foi usado para processar e avaliar os dados morfométricos dos cachos, frutos e sementes. O coeficiente da correlação de Pearson ( $r$ ) foi feito com o auxílio do programa BioEstat 5.0 (FELIZARDO et al., 2015). Para todos os parâmetros de comprimento e massa foram determinados valores máximo e mínimo, médias, desvio padrão (DP) e coeficiente de variação (CV). Os dados de percentagem da germinação foram transformados em arco-seno $\sqrt{ }(\mathrm{x} / 100)$.

\section{RESULTADOS E DISCUSSÃO}

$\mathrm{Na}$ Tabela 1 pode ser observado que os pesos dos cachos e o número total dos frutos apresentaram os maiores coeficientes de variação $(26,83 \%$ e $34,81 \%$, respectivamente). O comprimento médio dos cachos foi de $131,8 \mathrm{~cm}$, o peso médio dos cachos foi de $13,1 \mathrm{~kg}$, a média de frutos/cacho foi de 1.258 e a quantidade média de raquilas 164. MENDONÇA et al. (2012), ao estudarem o potencial produtivo desta espécie no leste do Acre, encontraram valor médio de $8,7 \mathrm{~kg}$ para o peso do cacho, 963 para o número médio de frutos/cacho e 163 para a quantidade de raquilas. Uma possível explicação para os valores inferiores observados no trabalho de MENDONÇA et al. (2012), pode ter sido o fato de eles terem avaliado apenas três cachos, ante os nove utilizados no presente estudo.

TABELA 1 - Caracterização biométrica dos cachos de Syagrus sancona oriundos do Parque Zoobotânico da Universidade Federal do Acre, em Rio Branco, Acre. DP - desvio padrão, CV - coeficiente de variação.

\begin{tabular}{lccccc}
\hline & $\begin{array}{c}\text { Peso } \\
\text { cacho }(\mathbf{k g})\end{array}$ & $\begin{array}{c}\text { Comprimento } \\
\text { cacho }(\mathbf{c m})\end{array}$ & $\begin{array}{c}\text { Comprimento } \\
\text { raque (cm) }\end{array}$ & $\begin{array}{c}\text { Número de } \\
\text { raquila }\end{array}$ & $\begin{array}{c}\text { № total de } \\
\text { Frutos }\end{array}$ \\
\hline Mínimo & 8,6 & 117,2 & 71,8 & 148 & 643 \\
Máximo & 20,00 & 149 & 98 & 197 & 1987 \\
Média & 13,07 & 131,8 & 84,83 & 164 & 1258 \\
DP & 3,51 & 11,21 & 8,39 & 14,0 & 438 \\
CV(\%) & 26,83 & 8,51 & 9,89 & 8,74 & 34,81 \\
\hline
\end{tabular}

O diâmetro médio da base, meio e ápice da raque dos cachos foram respectivamente de $3,41 \mathrm{~cm}, 2,39 \mathrm{~cm}$ e $1,31 \mathrm{~cm}$. O comprimento médio das raquilas da base, meio e ápice foi de $45,39,4$ e $24,8 \mathrm{~cm}$, respectivamente. Os maiores valores do coeficiente de variação foram observados no comprimento das raquilas da base e do ápice do cacho, e no diâmetro da porção apical da raque da inflorescência (Tabela 2). 
TABELA 2 - Caracterização biométrica do diâmetro da raque e comprimento das raquilas dos cachos de Syagrus sancona oriundos do Parque Zoobotânico da Universidade Federal do Acre, em Rio Branco, Acre. DP - desvio padrão; CV - coeficiente de variação; DBR - diâmetro médio da base da raque; DMR - diâmetro médio do meio da raque; DAR diâmetro médio do ápice da raque; $\mathrm{CRQB}$ - comprimento médio das raquilas da base; CRQM - comprimento médio das raquilas do meio; CRQA - comprimento médio das raquilas do ápice.

\begin{tabular}{lcccccc}
\hline & $\begin{array}{c}\text { DBR } \\
(\mathbf{c m})\end{array}$ & $\begin{array}{c}\text { DMR } \\
(\mathbf{c m})\end{array}$ & $\begin{array}{c}\text { DAR } \\
(\mathbf{c m})\end{array}$ & $\begin{array}{c}\text { CRQB } \\
(\mathbf{c m})\end{array}$ & $\begin{array}{c}\text { CRQM } \\
(\mathbf{c m})\end{array}$ & $\begin{array}{c}\text { CRQA } \\
(\mathbf{c m})\end{array}$ \\
\hline Mínimo & 3,05 & 2,03 & 1,05 & 12 & 24,2 & 9,5 \\
\hline Máximo & 3,9 & 3,3 & 2,03 & 65,5 & 51,7 & 54 \\
\hline Média & 3,41 & 2,39 & 1,31 & 45,03 & 39,47 & 24,79 \\
\hline DP & 0,30 & 0,42 & 0,32 & 13,42 & 6,39 & 10,47 \\
\hline CV (\%) & 8,94 & 17,53 & 24,34 & 29,81 & 16,19 & 42,21 \\
\hline
\end{tabular}

Os frutos apresentaram peso, comprimento e diâmetro médios de 10,2 g, 3,3 $\mathrm{cm}$ e 2,2 cm, respectivamente. $O$ peso médio da polpa foi de $3,5 \mathrm{~g}$ e a profundidade média $0,23 \mathrm{~cm}$. O peso médio da casca foi de $0,59 \mathrm{~g}$. Os maiores valores de CV ocorreram no peso da casca $(58.64 \%)$, na profundidade da polpa $(26,82 \%)$ e no peso da polpa (25,65\%) (Tabela 3). Os altos valores de CV do peso da casca e do peso da polpa se devem à dificuldade da separação da casa e da polpa, que por ser pegajosa e oleosa, sempre apresenta resíduos aderidos à casca. Em relação à profundidade da polpa, o alto valor do CV provavelmente decorreu de variações na posição do paquímetro durante a tomada das medidas, visto que os CVs do diâmetro dos frutos e das sementes são baixos $(7,11 \%$ e 4,96\%, respectivamente). NASCIMENTO et al. (2007) também encontraram alto CV para o peso da casca em seu estudo da biometria de cachos, frutos e sementes da palmeira Astrocaryum ulei, uma espécie com polpa carnosa e oleosa como a de $S$. sancona (KAHN, 2008)

TABELA 3 - Caracterização biométrica dos frutos de Syagrus sancona oriundos do Parque Zoobotânico da Universidade Federal do Acre, em Rio Branco, Acre. DP - desvio padrão; CV - coeficiente de variação.

\begin{tabular}{lcccccc} 
& $\begin{array}{c}\text { Peso } \\
\text { fruto } \\
(\mathbf{g})\end{array}$ & $\begin{array}{c}\text { Peso } \\
\text { Casca } \\
(\mathbf{g})\end{array}$ & $\begin{array}{c}\text { Peso } \\
\text { Polpa } \\
(\mathbf{g})\end{array}$ & $\begin{array}{c}\text { Comprimento } \\
\text { (cm) }\end{array}$ & $\begin{array}{c}\text { Diâmetro } \\
\text { (cm) }\end{array}$ & $\begin{array}{c}\text { Profundidade } \\
\text { da polpa } \\
\text { (cm) }\end{array}$ \\
\hline Mínimo & 6,8 & 0,27 & 1,42 & 2,8 & 1,8 & 0,1 \\
Máximo & 14,2 & 4,9 & 5,91 & 3,9 & 2,9 & 0,4 \\
Média & 10,2 & 0,59 & 3,5 & 3,3 & 2,2 & 0,23 \\
DP & 1,57 & 0,35 & 0,93 & 0,29 & 0,15 & 0,06 \\
CV (\%) & 15,35 & 58.64 & 25,65 & 8,66 & 7,11 & 26,82 \\
\hline
\end{tabular}

Os valores médios do peso do fruto e da polpa apresentam uma diferença pouco significativa quando comparado aos valores encontrados por MENDONÇA et al. (2012), que encontraram frutos com peso médio de 9,4 $\mathrm{g}$ e peso da polpa de 4,6 g. Segundo MOURA et al. (2010) as informações das características de peso, tamanho e diâmetros dos frutos são valorizadas pelas indústrias de sorvetes, licores e sulcos, pois ajudam na separação de frutos com maior quantidade de polpa. 
Com relação à biometria de sementes, observa-se na Tabela 4 que 0 comprimento e o diâmetro destas, variaram de 2,5 a 3,7 cm (média $3,1 \mathrm{~cm}$ ) e 1,1 a $1,7 \mathrm{~cm}$ (média 1,5 cm) respectivamente. MENDONÇA et al. (2012) encontraram valores para o comprimento variando entre 1,7 e 2,7 cm, esses valores foram inferiores aos deste estudo.

TABELA 4 - Caracterização biométrica das sementes de Syagrus sancona oriundos do Parque Zoobotânico da Universidade Federal do Acre, em Rio Branco, Acre. DP - desvio padrão, CV - coeficiente de variação.

\begin{tabular}{lccc}
\hline & $\begin{array}{c}\text { Peso } \\
\text { semente }(\mathbf{g})\end{array}$ & $\begin{array}{c}\text { Comprimento } \\
\text { semente }(\mathbf{c m})\end{array}$ & $\begin{array}{c}\text { Diâmetro } \\
\text { (cm) }\end{array}$ \\
\hline Mínimo & 3,0 & 2,5 & 1,1 \\
Máximo & 6,5 & 3,7 & 1,7 \\
Média & 5,1 & 3,1 & 1,5 \\
DP & 0,51 & 0,26 & 0,08 \\
CV (\%) & 10,14 & 8,31 & 4,96 \\
\hline
\end{tabular}

O resultado da análise do coeficiente de correlação de Pearson $(r)$ das amostras de frutos e sementes (Tabela 5) mostrou positiva e forte correlação entre o diâmetro do fruto e o peso da semente $(r=0.8779)$, o peso e o comprimento do fruto $(r=0.7858)$, e o peso do fruto e peso da semente $(r=0.7231)$, indicando que quanto maiores forem o comprimento e o diâmetro dos frutos, maiores serão os pesos das sementes, frutos e polpa. Essas informações são muito importantes, pois permitem auxiliar na escolha e classificação de frutos e sementes. CARRIJO et al. (2011), ao estudarem a caracterização de frutos e sementes de Syagrus oleracea, verificaram correlação positiva entre comprimento e diâmetro, além da razão entre o comprimento-diâmetro e a massa, sugerindo que quando o comprimento for maior, maiores serão também o diâmetro, a razão comprimento-diâmetro e a massa. CARRIJO et al. (2013) verificaram se o tamanho do fruto influencia na germinação de oriundas de frutos verdes e maduros de $S$. oleracea e concluíram que frutos de menor comprimento e frutos maduros apresentaram maior percentual de germinação.

TABELA 5 - Correlação entre as variáveis dos frutos e sementes de Syagrus sancona oriundos do Parque Zoobotânico da Universidade Federal do Acre, em Rio Branco, Acre. PF - peso do fruto (g); CF - comprimento do fruto (cm); DF - diâmetro do fruto (cm); PP profundidade da polpa (cm); PS - peso da semente (g); CS comprimento da semente $(\mathrm{cm})$; DS - diâmetro da semente $(\mathrm{cm})$.

\begin{tabular}{lccccccc}
\hline & $\begin{array}{c}\text { PF } \\
(\mathbf{g})\end{array}$ & $\begin{array}{c}\text { CF } \\
(\mathbf{c m})\end{array}$ & $\begin{array}{c}\text { DF } \\
(\mathbf{c m})\end{array}$ & $\begin{array}{c}\text { PP } \\
(\mathbf{c m})\end{array}$ & $\begin{array}{c}\text { PS } \\
(\mathbf{g})\end{array}$ & $\begin{array}{c}\text { CS } \\
(\mathbf{c m})\end{array}$ & $\begin{array}{c}\text { DS } \\
(\mathbf{c m})\end{array}$ \\
\hline PF (g) & 1 & & & & & & \\
CF (cm) & 0.7858 & 1 & & & & & \\
DF (cm) & 0.5993 & 0.3602 & 1 & & & & \\
PP (cm) & 0.5904 & 0.4946 & 0.3454 & 1 & & & \\
PS (g) & 0.7231 & 0.5339 & 0.8779 & 0.4014 & 1 & & \\
CS (cm) & 0.4406 & 0.3008 & 0.5047 & 0.2838 & 0.523 & 1 & \\
DS (cm) & 0.2634 & 0.2318 & 0.3296 & 0.1512 & 0.3267 & -0.0764 & 1 \\
\hline
\end{tabular}


O teor médio de água do lote de semente de $S$. sancona foi de $21,88 \%$, um valor aproximado aos 19,9\% obtidos por BATISTA (2009) em seu estudo de Syagrus oleracea e muito superior aos 12,7\% encontrados por GOUDEL (2012) para as sementes de $S$. romanzoffiana. $O$ teor de água para as sementes de $S$. sancona está dentro dos níveis ótimos, pois o valor crítico de umidade para sementes recalcitrantes é de 12 a 30\%, dependendo da espécie (ROBERTS, 1973).

O início da germinação das sementes de $S$. sancona ocorreu após 113 dias da semeadura e prolongou-se por mais 109 dias. PINTO et al. (2012), avaliando diferentes tratamentos para a superação da dormência das sementes de $S$. oleracea, observaram que o número mínimo de dias para o início da germinação nesta espécie foi de 81 . Este resultado sugere que $S$. sancona parece apresentar dormência mais severa em suas sementes. De uma maneira geral os percentuais de germinação, entre 17 e 35\% foram muito baixos para todos os tratamentos (Tabela $6)$.

TABELA 6 - Porcentagem de germinação, índice de velocidade de germinação (IVG) e tempo médio de germinação (TMG) de sementes de Syagrus sancona oriundas do Parque Zoobotânico da Universidade Federal do Acre, em Rio Branco, Acre, submetidas a diferentes tratamentos.

\begin{tabular}{lccc}
\hline Tratamentos & Germinação (\%) & TMG & IVG \\
\hline Testemunha (semente intacta) & 17 & 143 & 0.00705 \\
Testemunha (frutos intactos) & 19 & 149 & 0.00680 \\
Semente imersa em água por 12 h & 22 & 165 & 0.00609 \\
Frutos imersos em água por 12 h & 22 & 167 & 0.00606 \\
Semente imersa em água por 24 h & 35 & 146 & 0.00687 \\
Frutos imersos em água por 24 h & 18 & 159 & 0.00632 \\
Sementes imersas em água por 48 h & 18 & 148 & 0.00675 \\
Frutos imersos em água por 48 h & 28 & 159 & 0.00635 \\
Sementes escarificadas & 28 & 162 & 0.00619 \\
Frutos escarificados & 32 & 144 & 0.00704 \\
Sementes imersas em água por 72 h & 33 & 149 & 0.00673 \\
Frutos imersos em água por 72 h & 28 & 149 & 0.00679 \\
\hline
\end{tabular}

As sementes imersas em água por 24 e 72 horas e os frutos escarificados apresentaram maior porcentagem de germinação $(35 \%, 33 \%$ e $32 \%$, respectivamente). O menor percentual de emergência (17\%) foi observado em sementes não submetidas a qualquer tratamento, seguido pelo percentual de $18 \%$ para os frutos imersos em água por $24 \mathrm{~h}$ e as sementes imersas em água por $48 \mathrm{~h}$.

Os valores de porcentagem de germinação do presente estudo são considerados baixos quando comparados aos valores encontrados por CREPALDI (2001) para a espécie Syagrus coronata, na qual os tratamentos de imersão em água por 24 e 48 horas resultaram, respectivamente, em porcentagem de germinação de 77\% e 75\%. GOUDEL (2012), estudando a germinação das sementes de Syagrus romanzoffiana observou um índice de germinação de 50\% quando as sementes tiveram seu opérculo perfurado e foram embebidas em água por 24 horas, este resultado foi superior ao tratamento do presente trabalho em que 
as sementes foram apenas embebidas por 24 horas. PINTO et al. (2012), ressaltam que a imersão das sementes em água acelera o desenvolvimento inicial da plântula e que o tempo de germinação é reduzido quando se realiza o despolpamento do fruto.

Quanto aos resultados do tempo médio de emergência (TME) das plântulas, o tratamento com frutos imersos em água por 12h apresentou maior TME (167 dias). Os menores tempos foram observados no caso das sementes do tratamento testemunha (143 dias) e frutos escarificados (144 dias), que também apresentaram os maiores índice de velocidade de germinação (IVG) (0.00705 e 0.00704, respectivamente). PIVETTA et al. (2005) constaram, no caso de Syagrus schizophylla, maior porcentagem e germinação mais rápida em sementes escarificadas mecanicamente do que em sementes não escarificadas. BECKMANNCAVALCANTE et al. (2012), avaliando efeito da escarificação mecânica em sementes de juçara (Euterpe edulis), também observaram que a técnica de escarificação favorece a germinação e o índice de velocidade.

A escarificação mecânica é recomendada para sementes de palmeiras com tegumentos duros e impermeáveis (MEEROW \& BROSCHAT, 2012). Este parece ter sido o caso observado no presente estudo, onde os frutos escarificados apresentaram germinação e tempo médio de emergência (32\% e 144 dias, respectivamente) entre os mais elevados dos tratamentos utilizados.

\section{CONCLUSÕES}

A avaliação biométrica revelou que as dimensões dos frutos do lote avaliado são uniformes, entretanto, o peso dos cachos e dos frutos mostrou alta variabilidade, indicando que as plantas matrizes utilizadas neste estudo apresentam alta variabilidade genética, sugerindo a necessidade de pré-selecionar sementes caso se pretenda fazer a propagação vegetativa da espécie.

As sementes de $S$. sancona apresentaram baixo percentual de germinação e demorado tempo médio de germinação (113 dias), situação normal em palmeiras, que usualmente superam os 100 dias. A duração da emergência das plântulas também se mostrou lenta, pois se estendeu por mais de oito meses.

A imersão das sementes em água por 24 e 72 horas, respectivamente, assim como a escarificação dos frutos para remover a película protetora do poro germinativo resultaram em maiores percentuais de emergência de plântulas.

Diante da escassez na literatura científica abordando a biometria e outros aspectos relacionados com a propagação de $S$. sancona, pode-se inferir que 0 desenvolvimento de sistemas de propagação vegetativo eficiente para esta espécie demandará um intenso esforço de pesquisa.

\section{REFERÊNCIAS}

BATISTA, G. S. Morfologia e germinação de sementes de Syagrus oleracea (Mart.) Becc. (Arecaceae). 2009. 37f. Dissertação (Mestrado Agronomia), Universidade Estadual Paulista "Júlio de Mesquita Filho", Jaboticabal, SP, 2009. Disponível em: <http://www.fcav.unesp.br/download/pgtrabs/pv/m/78295.pdf>. Acesso em: 8 mar 2017.

BECKMANN-CAVALCANTE, M. Z.; PIVETTA, K. F. L.; ILHA, L. L.; TAKANE, R. J. Temperatura, escarificação mecânica e substrato na germinação de sementes das 
palmeiras juçara e açaí. Revista Brasileira de Ciências Agrárias. Recife, v. 7, n. 4, p. 569-573, 2012. Disponível em: <http://dx.doi.org/10.5039/agraria.v7i4a1684>. doi: 10.5039/agraria.v7i4a1684.

BeZERRA, F. T. C.; ANDRADE, L.; BeZERRA, M. A. F.; PEREIRA, W. E.; FABRICANTE, J. R.; OLIVEIRA, L. S. B.; FEITOSA, R. C. Biometria de frutos e sementes e tratamentos pré-germinativos em Cassia grandis L. f. (Fabaceae). Semina: Ciências Agrárias, v. 33, p. 2863-2876, 2012. Disponível em: <http://dx.doi.org/10.5433/1679-0359.2012v33Supl1p2863>. doi: 10.5433/16790359.2012v33Supl1p2863.

BRASIL. Ministério da Agricultura e Reforma Agrária. Regras para análise de sementes. Brasília: CLAV/DNDV/SNAD/MA, 1992, 365p.

BUSATTO, P. C.; NUNES, A. S.; COLMAN, B. A.; MASSON, G. L. Superação de dormência em sementes de jatobá (Hymenaea courbaril L.). Revista Verde de Agroecologia e Desenvolvimento Sustentável, v. 8, n. 1, p. 154-160, 2013. Disponível em: <http://gvaa.org.br/revista/index.php/RVADS/article/view/1807> Acesso em: 04 mar.2017.

CARRIJO, N. S.; REIS, E. F.; COSTA-NETTO, A. P. Germinação de frutos verdes e maduros de Syagrus oleracea Becc. em função do tamanho. Global Science and Technology, v. 6, n. 1, p. 118-126, 2013. Disponível em:

<http://dx.doi.org/10.14688/1984-3801.v06n01a10>. doi: 10.14688/19843801.v06n01a10.

CARRIJO, N. S. Germinação e caracterização física e morfológica de frutos e sementes de Syagrus oleracaea Becc. 2011, 63f. Dissertação (Mestrado em Agronomia), Programa de Pós-graduação em Agronomia - Produção Vegetal, Universidade Federal de Goiás, Jataí-GO, 2011. Disponível em: <https://repositorio.bc.ufg.br/tede/handle/tede/3511>. Acesso em: 07 mar 2017.

CREPALDI, I. C.; MURADIAN, L. B. A.; RIOS, M. D. G.; PENTEADO, M. V. C. C.; SALATINO, A. Revista Brasileira de Botânica, v. 24, n. 2, p. 155-159, 2001. Disponível em: <http://www.scielo.br/pdf/rbb/v24n2/a04v24n2.pdf>. Acesso em: 8 mar 2017.

DOMINGOS-NETO, V. C.; FERREIRA, E. J. L. Biometria de cachos, frutos e sementes da palmeira jarina (Phytlephas mcrocarpa Ruiz \& Pav.) oriundos de fragmentos florestais primários e secundários do leste do Acre. Enciclopédia Biosfera, v. 10, n. 19, p.2765-2775, 2014. Disponível em: <http://www.conhecer.org.br/enciclop/2014b/MULTIDISCIPLINAR/biometria\%20de\% 20cachos\%20frutos.pdf>. Consulta em: 8 de mar 2017.

FELIZARDO, S. A.; FREITAS, A. D. D.; MARQUES, N. S,; BEZERRA, D. A. Características biométricas de frutos e sementes de Oenocarpus bataua Mart. com procedência de Almeirim, Pará. Revista Verde de Agroecologia e Desenvolvimento Sustentável, v. 10, n. 5, p.9-15, 2015. Disponível em: <http://dx.doi.org/10.18378/rvads.v10i5.3672> doi: 10.18378/rvads.v10i5.3672. 
FERREIRA, E. J. L.; MENDONÇA, C. C.; BARBOSA, C. S.; MENEZES, H. G.; LIMA, A. F.; SILVA, G. M. Estudos fenológicos e biométricos da jaciarana (Syagrus sancona. Arecaceae), uma palmeira nativa do acre com potencial para a produção de biocombustível. Sociedade de Ecologia do Brasil-SEB, v. 1, p. 1-450, 2013.

FERREIRA, E. J. L. F. Manual das palmeiras do Acre, Brasil. 2005. Disponível em: <http://www.nybg.org/bsci/acre/www1/manual_palmeiras.html>. Acesso em: 6 mar 2017.

FIOR, C. S.; SOUZA, P V. D.; SCHWARZ, S. F. Emergência de plântulas de Butia odorata (Barb. Rodr.) Noblick em casa de vegetação. Revista Árvore, v. 37, n. 7, p.503-510, 2013. Disponível em: <http://dx.doi.org/10.1590/S010067622013000300013>. doi: 10.1590/S0100-67622013000300013.

GONÇALVES, L. G. V.; ANDRADE, F. R.; MARIMON JUNIOR, B. H.; SCHOSSLER, T. R.; LENZA, E.; MARIMON, B. S. Biometria de frutos e sementes de mangaba (Hancornia speciosa Gomes) em vegetação natural na região leste de Mato Grosso, Brasil. Revista de Ciências Agrárias, v. 36, n. 1, p.36-40, 2013. Disponível em: <http://www.scielo.mec.pt/pdf/rca/v36n1/v36n1a06.pdf>. Acesso em 2 mar 2017.

GORDIN, C. R. B.; MARQUES, R. F.; MASETTO, T. E.; SCALON, S. P. Q.; Germinação, biometria de sementes e morfologia de plântulas de Guizotia abyssinica Cass. Revista Brasileira de Sementes, v. 34, n. 4, p. 619-627, 2012. Disponível em: <http://dx.doi.org/10.1590/S0101-31222012000400013>. doi: 10.1590/S0101-31222012000400013.

GOUDEL, F. Caracterização e Processamento de mapuitã, os frutos da palmeira jerivá (Syagrus romanzoffiana Cham.). 2012. 115f. Dissertação (Mestrado em Agroecossistemas), Programa de Pós-Graduação em Agroecossistema, Universidade Federal de Santa Catarina, Florianópolis-SC, 2012. Disponível em: <http://repositorio.ufsc.br/xmlui/handle/123456789/96153>. Acesso em: 22 mar 2017.

HENDERSON, A. The palms of the Amazon. New York: Oxford University Press, 1995, 232p.

KAHN, F. The genus Astrocaryum (Arecaceae). Revista Peruana de Biologia, v. 15, n. 1, p. 31-48, 2008. Disponível em:

<http://sisbib.unmsm.edu.pe/BVRevistas/biologia/v15sup1/pdf/a04v15sup1.pdf>. Acesso em: 21 mar 2017.

LEBID, T.; HENKES, J. A. Óleo de dendê na produção de biodiesel: um estudo de caso das vantagens e desvantagens econômica, ecológica e social da cultura desta oleaginosa para a produção de biodiesel. Revista Gestão \& Sustentabilidade Ambiental, v. 4, n. 1, p. 392-415, 2015. Disponível em: $<$ http://www.portaldeperiodicos.unisul.br/index.php/gestao_ambiental/article/view/293 6>. Acesso em: 8 mar 2017. 
MEEROW, A. W.; BROSCHAT, T. K. Palm seed germination. Gainesville: University of Florida/IFAS Extension, 2012, 9p. (University of Florida/IFAS Extension Bulletin, 274). Disponível em: <http://edis.ifas.ufl.edu/ep238>. Acesso em: 20 mar 2017.

MENDONÇA, C. C.; FERREIRA, E. J. L.; LIMA, A. F.; BARBOSA, C. S.; SILVA, G. M.; BANDEIRA, J. R. Potencial produtivo e viabilidade da exploração da palmeira "jaciarana" (Syagrus sancona) para a produção de biodiesel no leste do Acre. Instituto Nacional de Pesquisas da Amazônia/PAIC/FAPEAM, 2012, 235p.

MOURA, R. C.; LOPES, P. S. N.; BRANDÃO-JUNIOR, D. S.; GOMES, J. G. e PEREIRA, M. B. Biometria de frutos e sementes de Butia capitata (Mart.) Beccari (Arecaceae), em vegetação natural no Norte de Minas Gerais, Brasil. Biota Neotropica, v. $10, \quad$ n. 2, p. 415-419, 2010. Disponível em: <http://dx.doi.org/10.1590/S1676-06032010000200040>. DOI: $10.1590 / S 1676-$ 06032010000200040.

NASCIMENTO, J. F.; FERREIRA, E. J. L.; CARVALHO, A. L.; REGIANI, A. M. Parâmetros biométricos dos cachos, frutos e sementes da palmeira murmuru (Astrocaryum ulei Burret) encontrada na região de Porto Acre, Acre. Revista Brasileira de Biociências, v. 5, p. 90-92, 2007. Disponível em: <http://www.ufrgs.br/seerbio/ojs/index.php/rbb/article/view/117/113>. Acesso em: 26 mar 2017.

PINTO, J. F. N.; REIS, E. F.; NETTO, A. P. C.; PINTO, J. F. N.; ASSUNÇÃO, H. F.; NUNES, H. F. Efeito de diferentes tratamentos na superação da dormência de sementes da palmeira Syagrus oleracea Becc. Cerne, v. 18, n. 3, p. 487-493, 2012. Disponível em: <http://dx.doi.org/10.1590/S0104-77602012000300017>. doi: 10.1590/S0104-77602012000300017.

PIVETTA, K. F. L.; SARZI, I.; CINTRA, G. S.; PEDRINHO, D. R.; CASALI, L. P.; PIZETTA, P. U. C.; PAULA, R. C. Effects of maturation and scarification on seed germination of Syagrus schizophylla (Mart.) Glass. (Arecaceae). Acta Horticulturae, v. 683, p. 375-378, 2005. Disponível em: <http://dx.doi.org/10.17660/ActaHortic.2005.683.48>. doi: 10.17660/ActaHortic.2005.683.48.

ROBERTS, E. H. Predicting the storage life of seeds. Seed Science and Technology, v. 1, n. 4, p. 499-514, 1973.

RODRIGUES, R. A.; AMARAL, E. A.; GALVÃO, A. S.; Acarofauna em açaizeiro (Euterpe oleracea Mart.) conduzido em diferentes sistemas de cultivo. Revista Agro@mbiente On-line, v. 10, n. 3, p. 273-281, 2016. Disponível em: <http://dx.doi.org/10.18227/1982-8470ragro.v10i3.3074>. doi: 10.18227/19828470ragro.v10i3.3074.

SILVA, P. S. R.; ARAÚJO, C.; PIMENTA, A.C. Germinação de sementes de mangabeira em função do substrato e da temperatura. Enciclopédia Biosfera, $v$. $13, \quad$ n. 24, p. 564-571, 2016. Disponível em: 
$<$ http://dx.doi.org/10.18677/EnciBio_2016B_052>.

doi:

10.18677/EnciBio_2016B_052.

SMIDERLE, O. J.; SILVA, V. X.; CHAGAS, E. A.; SOUZA, A. G.; RIBEIRO, M. I. G.; CHAGAS, P. C.; SOUZA, O. M. Açai seedling production: effect of substrates and seeds size on germination and growth of seedlings. Journal of Advances in Agriculture, v. 4, n. 1, p. 316-323, 2015. Disponível em:

<https://cirworld.com/index.php/jaa/article/view/4300/4191>. Acesso em: 28 mar 2017. 